\title{
Symptomatic Pulmonary Embolism after Achilles Tendon Repair
}

\author{
Naoki Yoshida* and Yoshihiko Tsuchida \\ Shonan Kamakura General Hospital, Japan
}

Submission: May 21, 2018; Published: May 29, 2018

*Corresponding author: Naoki Yoshida, Shonan Kamakura General Hospital, 1370-1 Okamoto, kamakura-city, Japan, Tel: +81-0467-46-1717; Fax: +81-0467-45-0190; Email: nyoshida.thk@gmail.com

\begin{abstract}
The incidence of symptomatic pulmonary embolism (PE) following treatment for Achilles tendon rupture is rare. Here we present a case of a 40-year-old man with symptomatic PE, who was operated 24 days ago for Achilles tendon rupture. Computed tomography angiography (CTA) showed numerous pulmonary emboli in the bilateral pulmonary artery from the main pulmonary artery and a thrombus in the inferior vena cava (IVC) from the left iliac vein. The patient was treated using an anticoagulant and IVC filter and showed a good functional outcome at the five-month follow-up. It is important to examine and treat Achilles tendon rupture, keeping in mind PE.
\end{abstract}

\section{Background}

Achilles tendon rupture is common in orthopedic practice [1]. In both operative and conservative treatments, cast immobilization is necessary to protect the repaired tendon [2]. There are a few reports on the incidence of symptomatic PE following treatment for Achilles tendon rupture $[3,4]$. This current report underscores the possibility of acute PE in cases of Achilles tendon rupture.

\section{Case Presentation}

A 40-year-old man presented to the emergency department with a painful left heel. The pain was suddenly brought on during aerobics, but he was able to walk despite the pain. He had no past medical history and was not on any medication at that time. On physical examination, there were a palpable gap in the left Achilles tendon, and Thompson test was positive. We diagnosed left Achilles tendon rupture and discussed the treatment with the patient. He agreed to have surgical repair and was operated upon nine days post injury. The tendon was sutured using the Kessler technique (Figure 1) and was subsequently protected by a below-the-knee cast in a plantar-flexed position. The patient was permitted to walk on crutches. He was discharged from our hospital, and he returned to work with no complications.

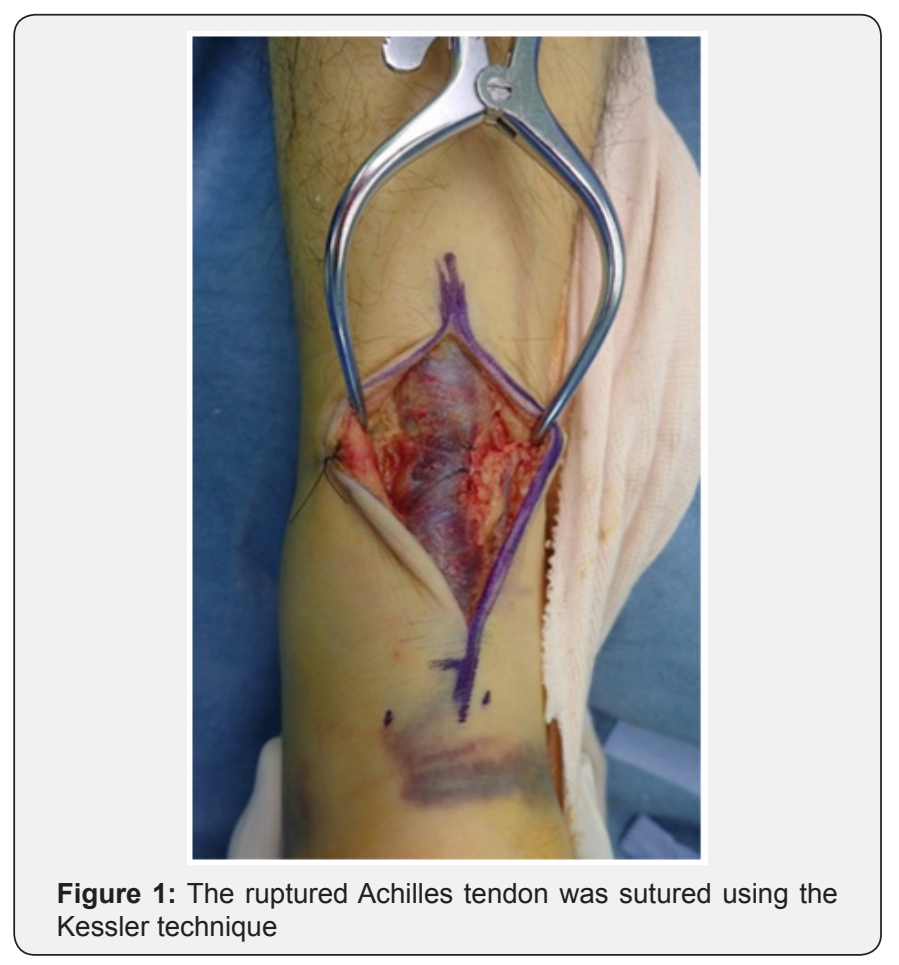


Two weeks postoperatively, his cast was converted into an Achilles tendonitis brace. However, 24 days postoperatively, he presented to the emergency department with sudden severe dyspnea. On examination, his blood pressure was $88 / 59 \mathrm{mmHg}$, pulse $98 / \mathrm{min}$, and respiratory rate $26 / \mathrm{min}$, with an 02 saturation of $93 \%$ in room air. CTA showed numerous pulmonary emboli in the bilateral pulmonary artery from the main pulmonary artery (Figure 2A). CTA also showed a vein thrombus in the IVC (Figure 2B) from the left iliac vein (Figure 2C). There was no thrombus in the right iliac vein. The patient was administered an anticoagulant and IVC filter as treatment for acute PE. The side of the Achilles tendon surgery coinciding with the side of the thrombus strongly suggested the Achilles tendon repair was the cause of PE. One month later, angioplasty revealed the thrombus had disappeared, so the IVC filter was removed. The patient showed a good functional outcome and returned to work at the six-month follow-up.
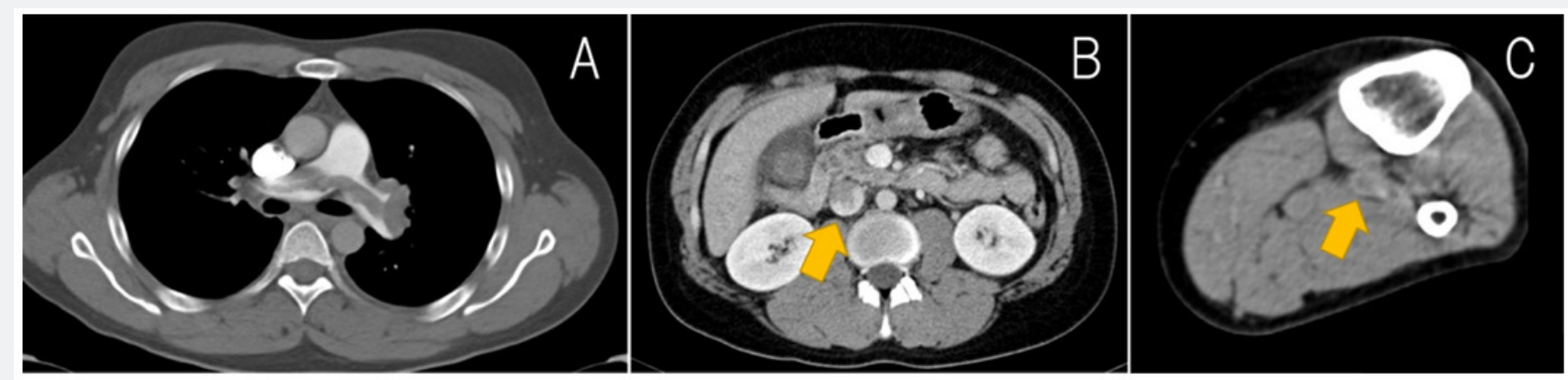

Figure 2: CTA showed (A) numerous pulmonary emboli in the bilateral pulmonary artery from the main pulmonary artery, (b) a thrombus in the IVC, and $(C)$ a thrombus in the left iliac vein.

\section{Discussion}

The Achilles tendon is the largest tendon in the body, but it often ruptures, mostly during sports activities [5]. Injury is caused by a sudden pushing off from the weight-bearing forefoot with the knee in extension, unexpected ankle dorsiflexion, and violent dorsiflexion of a plantar-flexed foot [6]. Achilles tendon rupture can be managed by both operative and nonoperative strategies. It is generally accepted that surgery should be performed for athletes and young and fit patients and that conservative treatment may be suitable for the elderly [7]. Both treatments include a period of immobilization, which is a welldocumented risk factor for deep vein thrombosis (DVT) [2]. In the current literature, the reported incidence of DVT after Achilles tendon rupture is highly variable, ranging from less than $1 \%$ to $34 \%$ [8]. Common symptoms and signs of DVT are unilateral or asymmetric swelling, leg edema, pain, erythema, fever, and leg warmth [9]. Actually, most DVT patients are asymptomatic, and only $9 \%-17 \%$ of them show clinical manifestation [9]. However, silent DVT can progress to a PE, a significant source of mortality [10].

There are several controversies surrounding thromboprophylaxis for Achilles tendon rupture. Several authors have recommended that the use of milder forms of prophylaxis, such as aspirin, also be explored [11]. Others have recommended that prophylactic anticoagulation not be routinely administered [12]. It is important to examine and treat Achilles tendon rupture, keeping in mind DVT and PE.

\section{References}

1. Houshian S, Tscherning T, Riegels-Nielsen P. (1998) The epidemiology of Achilles tendon rupture in a Danish county. Injury 29(9): 651-654.
2. Coon WW (1984) Venous thromboembolism. Prevalence, risk factors, and prevention. Clin Chest Med 5(3): 391-401.

3. Venkatachalam S, Wright KU (2012) Fatal pulmonary embolism following conservatively managed tendoachilles rupture-A case report. Int J Surg Case Rep 3(1): 3-5.

4. Yusof MI (2007) Acute pulmonary embolism following Achilles tendon repair. Singapore Med J 48(8): e234-e236.

5. Ames PR, Longo UG, Denaro V, Maffulli N (2008) Achilles tendon problems: not just an orthopaedic issue. Disabil Rehabil 30(20-22): 1646-1650.

6. Jiang N, Wang B, Chen A, Dong F, Yu B (2012) Operative versus nonoperative treatment for acute Achilles tendon rupture: a metaanalysis based on current evidence. Int Orthop 36(4): 765-773.

7. Raisbeck CC (2000) Rupture of the Achilles tendon. J Bone Joint Surg Am 82-A(12): 1804-1805.

8. Makhdom AM, Garceau S, Dimentberg R (2013) Fatal Pulmonary Embolism following Achilles Tendon Repair: A Case Report and a Review of the Literature. Case Rep Orthop 2013: 401968.

9. Qu H, Li Z, Zhai Z, Liu C, Wang S, et al. (2015) Predicting of Venous Thromboembolism for Patients Undergoing Gynecological Surgery. Medicine (Baltimore) 94(39): e1653.

10. Geerts WH, Bergqvist D, Pineo GF, Heit JA, Samama CM, et al. (2008) Prevention of venous thromboembolism: American College of Chest Physicians Evidence-Based Clinical Practice Guidelines (8th Edition). Chest 133(6 Suppl): 381S-453S.

11. Healy B, Beasley R, Weatherall M (2010) Venous thromboembolism following prolonged cast immobilisation for injury to the tendo Achillis. J Bone Joint Surg Br 92(5): 646-650.

12. Patel A, Ogawa B, Charlton T, Thordarson D (2012) Incidence of Deep Vein Thrombosis and Pulmonary Embolism after Achilles Tendon Rupture. Clin Orthop Relat Res 470(1): 270-274. 
This work is licensed under Creative Commons Attribution 4.0 License DOI: 10.19080/JOJCS.2018.07.555704

\section{Your next submission with Juniper Publishers will reach you the below assets}

- Quality Editorial service

- Swift Peer Review

- Reprints availability

- E-prints Service

- Manuscript Podcast for convenient understanding

- Global attainment for your research

- Manuscript accessibility in different formats ( Pdf, E-pub, Full Text, Audio)

- Unceasing customer service

Track the below URL for one-step submission https://juniperpublishers.com/online-submission.php 